\title{
Osteoarthrosis of the
}

\section{hip joint and sexual activity}

\author{
H. L. F. CURREY \\ The London Hospital Medical College, London, E.1
}

Despite the detailed studies that have been made into almost every other aspect of the lives of arthritic patients, little attention has been paid to the impact of joint disease on their sex life. Reticence about sexual matters, and the circumstances in which consultations are usually carried out, often in the presence of a nurse or physiotherapist, do not encourage routine enquiry about such intimate matters. That the more severe forms of arthritis will interfere with sexual activity is self evident, but there appears to be little or no information about the extent of this problem.

This study has been undertaken to provide information about the impact of one type of joint disease-osteoarthrosis of the hip-on the sexual relationship of married couples. The data were collected by a questionnaire sent to patients who had undergone surgery for osteoarthrosis of this joint, so that all who answered had at least moderately severe disease of a joint which anatomically might be expected to interfere with sexual intercourse.

The questionnaire was designed to find out how many of these patients had experienced sexual difficulty because of their arthritis, the nature and severity of any such difficulty, and the extent to which surgery provided any relief. Particular attention was paid to the question whether those whose arthritis had interfered with their sex life would have welcomed advice about this problem, and the form in which such advice would have been most acceptable.

\section{Method}

The questionnaire as illustrated was sent out with a covering letter explaining the purpose of the study. It was sent to all married patients aged 60 years or younger (at the time of mailing) who had undergone surgical treatment for osteoarthrosis of one or both hip joints at either The London or Notley Hospital during the previous 10 years.

\section{Results}

The questionnaire was sent to 235 patients, with the following response:

\begin{tabular}{lr} 
Adequately completed forms returned & 121 \\
Letter returned "Unknown at this address" & 20 \\
Questionnaire not applicable & 9 \\
Patient dead & 4 \\
Form inadequately completed & 2 \\
Patient unwilling to complete form & 6 \\
No reply & 73 \\
\hline \multicolumn{1}{c}{ Total } & 235 \\
\hline
\end{tabular}

Thus 33 forms either did not reach the person concerned or were not applicable, leaving 81 out of 202 (40 per cent.), either unaccounted for or returned uncompleted.

The nine patients for whom the questionnaire was not applicable had all, for one reason or another, ceased marital sexual relationships before the onset of arthritis.

Of the 121 patients whose replies are analysed here, 73 were women and 48 men. In 92 only one hip had been operated upon; 29 had bilateral operations. The age distribution at the onset of hip pain, at the time of operation, and at the time of completing the questionnaire is shown in the Figure (opposite).

\section{Frequency and severity of sexual difficulties}

Table I shows that, of the 121 patients, 81 (67 per cent.) experienced some degree of sexual difficulty due to their arthritis. In nine the arthritis had ended sexual intercourse. The Table also shows that sexual difficulties were relatively more common and more severe amongst women than amongst men. 


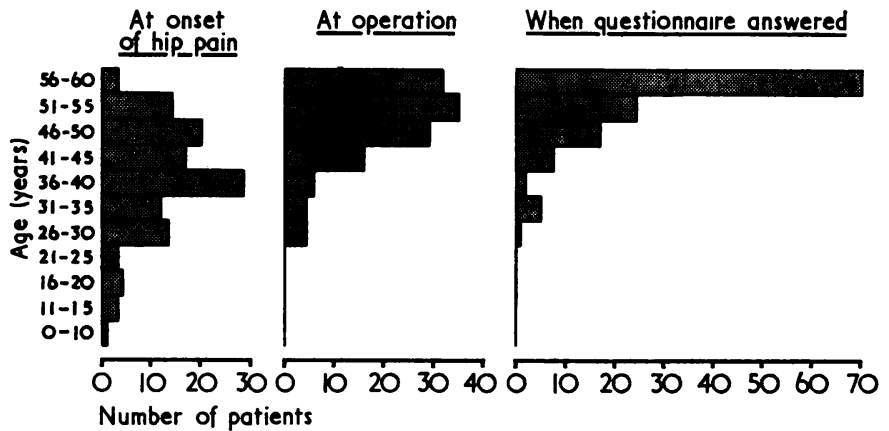

FIGURE Age distribution of 121 patients at time of onset of joint symptoms, at time of hip surgery, and at time of answering the questionnaire.

Table I Frequency and severity of sexual difficulties due to arthritis of the hip amongst 121 patients answering the questionnaire (Question 4), by sex

\begin{tabular}{|c|c|c|c|}
\hline Degree of sexual difficulty & Women & Men & Total \\
\hline None & 14 & 26 & 40 \\
\hline $\begin{array}{l}\text { Slight } \\
\text { Considerable } \\
\text { Sexual intercourse ended }\end{array}$ & $\left.\begin{array}{r}22 \\
30 \\
7\end{array}\right\} 59$ (81 per cent.) & $\left.\begin{array}{r}10 \\
10 \\
2\end{array}\right\} 22$ (46 per cent.) & $\left.\begin{array}{r}32 \\
40 \\
9\end{array}\right\} 81$ (67 per cent.) \\
\hline Total patients & $\overline{73}$ & 48 & 121 \\
\hline
\end{tabular}

Nature of difficulty with sexual intercourse

Table II analyses this problem in terms of actual joint pain produced by coitus, difficulty due to stiffness of the hip joint(s), and loss of libido. Local mechanical factors were clearly more important than any loss of sexual drive, and there were no important differences here between men and women.

Table II Analysis of mechanism by which arthritis of the hip interfered with sexual intercourse, by sex Individual patients often gave an affirmative answer for more than one mechanism. Few used the answer "uncertain" (see Question 5); two such answers were counted as one affirmative

\begin{tabular}{|c|c|c|c|}
\hline $\begin{array}{l}\text { Cause of sexual } \\
\text { difficulty }\end{array}$ & $\begin{array}{l}\text { Women } \\
\text { (59) }\end{array}$ & $\begin{array}{l}\text { Men } \\
\text { (22) }\end{array}$ & $\begin{array}{l}\text { Total } \\
(81)\end{array}$ \\
\hline $\begin{array}{l}\text { Pain } \\
\text { Stiffness } \\
\text { Loss of libido }\end{array}$ & $\begin{array}{l}29 \\
45 \\
12\end{array}$ & $\begin{array}{r}11 \\
15 \\
6\end{array}$ & $\begin{array}{l}40 \text { ( } 49 \text { per cent.) } \\
60 \text { (74 per cent.) } \\
18 \text { ( } 22 \text { per cent.) }\end{array}$ \\
\hline
\end{tabular}

\section{Effect on marriage}

Table III shows that about one-quarter of patients with sexual difficulties due to arthritis felt that these had produced definite unhappiness or tension in their marriages. Predictably (but not shown in the Table) the frequency of marital problems was in proportion to the degree of sexual difficulty.
Table III Analysis of patients with sexual difficulties due to arthritis who felt that this had produced significant unhappiness or tension in their marriages (Question 8), by sex

\begin{tabular}{|c|c|c|c|}
\hline $\begin{array}{l}\text { Sexual difficulty } \\
\text { due to arthritis } \\
\text { causing marital } \\
\text { unhappiness }\end{array}$ & $\begin{array}{l}\text { Women } \\
\text { (59) }\end{array}$ & $\begin{array}{l}\text { Men } \\
(22)\end{array}$ & $\begin{array}{l}\text { Total } \\
(81)\end{array}$ \\
\hline $\begin{array}{l}\text { Definite } \\
\text { Uncertain }\end{array}$ & $\begin{array}{l}14 \\
10\end{array}$ & $\begin{array}{l}5 \\
1\end{array}$ & $\begin{array}{l}19 \text { (23 per cent.) } \\
11 \text { (14 per cent.) }\end{array}$ \\
\hline
\end{tabular}

Influence of surgical treatment

Of the 81 patients with sexual difficulty due to arthritis, the influence of surgery on this difficulty was sufficiently clear-cut for analysis in 70 cases. (In the remainder this issue was confused by factors such as different operations being performed on opposite sides.) Table IV (overleaf) analyses the result of surgery in these 70 patients.

The overall figures show that surgical procedures relieved the general distress of pain in the hip more often than they helped specifically sexual difficulties due to arthritis. The numbers are too small to allow adequate comparison between the different operations in this respect. Nevertheless, total hip replacement, which was most successful in relieving hip pain, appears to have been more effective also 
Table IV Effect of surgical treatment of osteoarthrosis of the hip on hip pain (Question 3) and sexual difficulty due to arthritis (Question 7)

The operative procedures were: cup arthroplasty (35), osteotomy (16), total replacement (9), arthrodesis (5), Girdlestone arthroplasty (3), femoral head replacement (2)

\begin{tabular}{llll}
\hline $\begin{array}{l}\text { Degree of } \\
\text { relief }\end{array}$ & & $\begin{array}{l}\text { Hip pain } \\
\text { (Question 3) }\end{array}$ & $\begin{array}{l}\text { Sexual difficulty } \\
\text { (Question 7) }\end{array}$ \\
\cline { 1 - 1 } $\begin{array}{ll}\text { Complete } \\
\text { Considerable }\end{array}$ & 27 & 10 \\
Slight & 13 & 14 \\
None & 4 & 16 \\
\cline { 1 - 2 } Total & 70 & 30 \\
\hline
\end{tabular}

(compared, for example, to cup arthroplasty and osteotomy) in relieving specifically sexual difficulties. Arthrodesis on the other hand, while relieving hip pain, tended to have a disastrous effect on sexual function. For two women it ended sexual relationships.

\section{Need for advice on sexual problems}

Table V shows the numbers of patients who would have been grateful for advice given in various ways. This analysis is limited to the 59 women and 22 men with a sexual problem due to arthritis. Of these, a total of 13 (16 per cent.) wanted advice about the problem from their family doctor, 17 (21 per cent.) from a hospital doctor, 5 (6 per cent.) from a (female) medical social worker, and 39 (48 per cent.) favoured a booklet. There was little significant difference between the sexes.

Table $\mathbf{V}$ Numbers of patients (out of a total of 81 with sexual difficulties due to arthritis) who would have been grateful for various forms of advice about this problem (Question 10)

Few answered "doubtful"; two such replies were counted as one affirmative

\begin{tabular}{|c|c|c|c|}
\hline $\begin{array}{l}\text { Advice wanted } \\
\text { from }\end{array}$ & $\begin{array}{l}\text { Women } \\
(59)\end{array}$ & $\begin{array}{l}\text { Men } \\
(22)\end{array}$ & $\begin{array}{l}\text { Total } \\
\text { (81) }\end{array}$ \\
\hline $\begin{array}{l}\text { Family doctor } \\
\text { Hospital doctor } \\
\text { Medical social }\end{array}$ & $\begin{array}{l}11 \\
12\end{array}$ & $\begin{array}{l}2 \\
5\end{array}$ & $\begin{array}{l}13 \text { (16 per cent.) } \\
17 \text { ( } 21 \text { per cent.) }\end{array}$ \\
\hline $\begin{array}{l}\text { worker } \\
\text { Booklet }\end{array}$ & $\begin{array}{r}4 \\
27\end{array}$ & $\begin{array}{r}1 \\
12\end{array}$ & $\begin{array}{c}5 \text { ( } 6 \text { per cent.) } \\
39 \text { (48 per cent.) }\end{array}$ \\
\hline
\end{tabular}

Table VI shows the feelings of these same 81 patients regarding advice for their spouses. A total of 15 (19 per cent.) favoured a combined interview with the spouse present, 9 (11 per cent.) wanted a separate interview, while 38 patients (47 per cent.) wanted the spouse to get a booklet. An interview for the spouse was somewhat more favoured by women.

Table VI Numbers of patients (out of a total of 81 with sexual difficulties due to arthritis) who favoured various forms of advice about this for the spouse (Question 11)

Few answered "doubtful"; two such replies were counted as one affirmative

\begin{tabular}{|c|c|c|c|}
\hline $\begin{array}{l}\text { Advice wanted } \\
\text { for spouse }\end{array}$ & $\begin{array}{l}\text { Women } \\
\text { (59) }\end{array}$ & $\begin{array}{l}\text { Men } \\
\text { (22) }\end{array}$ & $\begin{array}{l}\text { Total } \\
\text { (81) }\end{array}$ \\
\hline $\begin{array}{c}\text { Combined } \\
\text { interview }\end{array}$ & 12 & 3 & $15(1$ \\
\hline Separate interview & 8 & 1 & 9 (11 per cent.) \\
\hline Booklet & 26 & 12 & 38 (47 per cent.) \\
\hline
\end{tabular}

Amongst all the patients with sexual difficulty, 64 per cent. wanted some form of advice. This was the same for men and women. Predictably, the percentage wanting advice increased with the severity of the sexual difficulty.

Comments from patients

About one-quarter of the patients who answered the questionnaire offered additional comments, but a minority of these concerned their sexual problems. Amongst the few relevant replies (which came mainly from women aged about 50) were complaints that this problem had never been discussed by their doctors, and approval that the matter was now being investigated. One understandable complaint was the lack of advice from surgeons about when it would be safe to resume sexual relationships after operation. Some women were clearly frightened of damaging the operated joint. From their own experience two women indicated that it had been possible to overcome mechanical problems by what some might regard as unconventional techniques, and they suggested that advice was needed to encourage couples to be less inhibited in their approach to this problem.

\section{Discussion}

The shortcomings of a postal questionnaire for this type of investigation are the lack of detailed information provided by the necessarily simple questions, and the risk of misunderstanding by the patient even of such straightforward enquiries. However, compared to a personal interview, there is the advantage of convenience, and the fact that the patient can answer anonymously and in private questions which might be embarrassing in an interview. Which method is likely to produce the more correct answers is a matter for speculation 
(Chesser, 1956). The studies of Ellis (1947) certainly indicate considerable advantage for the questionnaire method. In a sphere as psychologically complex as sexual behaviour such answers may in any case be influenced by motives of which the subject is unaware.

Even allowing for these reservations, the main conclusions from this study appear clear-cut. Osteoarthrosis of the hip, by the time it has progressed to the stage requiring operative treatment, produces sexual difficulties in about two-thirds of patients. These difficulties are relatively more common in women and are usually due to actual stiffness and pain in the joint. Only a minority recognize this as a cause of marriage unhappiness. Hip surgery can sometimes dramatically relieve sexual difficulties, but less certainly than other symptoms. Two-thirds of patients with such sexual difficulties would welcome some form of advice, usually for the spouse as well, and most favour a booklet.

Convenience dictated that osteoarthrosis of the hip was selected for this initial study, but the clinician caring for patients with locomotor disorders will want to know the extent of the problem and the need for counselling amongst patients with other diseases of joints. Ankylosing spondylitis and lumbar disc lesions might be expected to produce difficulties in this sphere, and these might be entirely different from the sexual problems posed, for example, by rheumatoid arthritis, where systemic illness, multiple joint involvement, drugs, and other factors might interfere with sexual activity. It is hoped to obtain data about these other disorders by an extension of this enquiry, using both questionnaires and interviews.

The present study makes it clear that a very real need exists for advice about sexual problems amongst patients with osteoarthrosis of the hip. If, as seems likely, this applies to other forms of arthritis, then a large communicating gap exists between patients with joint disease and their doctors. While most arthritic patients with a sexual problem favoured a booklet, one-quarter were in favour of an interview with a hospital doctor. This was somewhat more popular than an interview with the family doctor and very much more popular than an interview with a (female) medical social worker, even amongst women. This suggests perhaps that patients favoured advice from the person with most knowledge of the local pathological lesion, rather than from their family doctor, or someone of their own sex. Of course, all these patients had undergone hip surgery, and for them the surgeon would be in a position to advise, for example, about the risks of damaging the operated joint during coitus.

A third of the patients with sexual problems ascribed to arthritis were not in favour of any form of advice about this matter. From the comments in some of their replies it is obvious that these included men and women who would have been embarrassed, and perhaps even offended, by being offered this sort of counselling. It is clear therefore that considerable tact and discretion would be needed in providing any form of advice.

\section{Summary}

Little is known about the interference with sexual activity which results from arthritis. In an effort to determine the impact on sexual relationships of one type of joint disease, a questionnaire was sent to 235 patients aged 60 years or less who had been operated upon for osteoarthrosis of the hip within the previous 10 years.

Analysis based on 121 adequately completed forms indicated sexual difficulties due to arthritis in two-thirds of the patients. These difficulties were relatively more common in women, and were usually due to hip pain and stiffness rather than to loss of libido. One-quarter of these patients recognized this as a definite cause of marital unhappiness. Hip surgery sometimes relieved the difficulty dramatically, but less certainly than general symptoms were improved. Two-thirds of patients with such sexual difficulties wanted advice in some form, usually for the spouse as well, and most favoured a booklet.

It appears likely that large numbers of arthritic patients have sexual problems due to their joint disease. Most of them want advice about this problem, but probably very few are receiving it.

I am grateful to the orthopaedic surgeons on the staff of both The London Hospital and Notley Hospital for allowing me to send the questionnaire to patients treated by them.

\section{References}

Chesser, E. (1956) "The Sexual, Marital and Family Relationships of the English Woman", p.21. Hutchinson's Medical Publications, London.

Ellis, A. (1947) Amer. Sociol. Rev., 12, 541 (Questionnaire versus interview methods in the study of human love relationships). 


\section{Appendix Proforma used for questionnaire}

PRIVATE and CONFIDENTIAL

\section{ARTHRITIS OF THE HIP - QUESTIONNAIRE \\ (REMEMBER-DO NOT SIGN THIS FORM)}

1. Are you willing to complete this questionnaire?

(N.B. Even if answer is 'no', please return this form)

2. What is your age now?

At what age did you marry?

At what age did you first have pain in your hip?

At what age did you have your hip operation(s)?

Has your arthritis affected one or both hips?

Have you had operations on one or on both hips?

3. Did your hip operation(s) relieve your hip pain:

\begin{tabular}{l|l|l|l|l|l|l|l|}
\hline Completely? & \\
\hline Considerably? & \\
\hline Slightly? & \\
\hline Not at all? & \\
\hline
\end{tabular}

(tick whichever applies)

(If both hips operated on, indicate overall result)

4. Has the arthritis in your hip(s) (either before or after operation) interfered at all with sexual relationships in your marriage?

Not at all:
Slightly:
Considerably:
Ended sexual relationships:

(tick whichever applies)

5. If arthritis has interfered with your sexual relationship, was this due to:

\begin{tabular}{l|l|l|l|} 
& Yes & Uncertain & No \\
\hline $\begin{array}{lll}\text { Actual pain arising in the hip during intercourse? } \\
\text { Stiffness of the hip(s) making intercourse difficult? } \\
\text { General loss of desire for intercourse? }\end{array}$ & & \\
\hline
\end{tabular}


6. If arthritis has interfered with your sexual relationship, at what age were you first aware of this?

7. If arthritis has interfered with your sexual relationship at any stage, do you think that your operation(s) relieved this difficulty:

\begin{tabular}{ll|} 
Completely? \\
Considerably? \\
Slightly? \\
Not at all?
\end{tabular}

(tick whichever applies)

8. Have sexual difficulties due to your arthritis been responsible for unhappiness or tension in your marriage?

Yes:

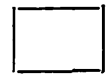

No:

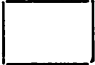

Uncertain :

(tick whichever applies)

9. Do you suffer from any other major illnesses, or are there other important factors which might affect your sexual relationship? If so, what?

10. Would you at any time have been grateful for advice about sexual problems due to arthritis, in the form of:

\begin{tabular}{l|l|l|l|}
\hline Discussion with your family doctor & Yes & Doubtful & No \\
\hline Discussion with a hospital doctor & & & \\
\hline Discussion with a Medical Social Worker (lady almoner) & & & \\
\hline A special booklet about this particular problem & & & \\
\hline
\end{tabular}

(for each question tick whichever applies)

11. If you favour a discussion or a booklet, would you wish your husband/wife to be:

\begin{tabular}{l|l|l|l|}
\hline Present during the discussion? & Yes & Doubtful & No \\
\hline Interviewed separately? & & & \\
\hline Given the booklet to read? & & & \\
\hline
\end{tabular}

(for each question tick whichever applies)

12. Have you any other comments? 